\title{
EL POEMA “TESTAMENTO” DE VALLE-INCLÁN: UNA HISTORIA TEXTUAL, CON SU PRIMER TESTIMONIO IMPRESO
}

\author{
VALLE-INCLÁN'S POEM “TESTAMENTO”: \\ A TEXTUAL HISTORY WITH THE EARLIEST \\ PRINTED TESTIMONY
}

\author{
Amparo de Juan Bolufer \\ Universidade de Santigo de Compostela \\ amparo.juan@usc.es
}

\begin{abstract}
Resumen: En este artículo se estudia la historia textual del poema "Testamento" de Valle-Inclán a partir de una relación actualizada de los testimonios de la tradición directa del texto, para luego editar el primer y desconocido testimonio impreso del poema. Se llega a la conclusión de que tanto los autógrafos como los impresos son en realidad copias de manuscritos de trabajo todavía en una fase redaccional, y se desvelan al menos dos estados genéticos cuya datación se intenta precisar. Asimismo, se presentan argumentos que parecen revelar que los testimonios impresos muestran diversas alteraciones debidas a la manipulación de sus editores.
\end{abstract}

Palabras clave: Ramón del Valle-Inclán; "Testamento”; variantes; crítica textual; crítica genética.

Abstract: This paper studies the textual history of the poem "Testamento" by Valle-Inclán. It presents a list of the printed and hand-written evidence of the direct tradition of the text and it edits the first (previously unknown) printed version of the poem. It is concluded that the autographs of the poem as well as the posthumous versions are in fact copies of rough drafts and not definitive texts. This indicates the existence of two separte stages in the writing of the poem, the dating of which this paper attempts to establish. Arguments are put forward to suggest that diverse alterations due are to manipulation on the part of the editors.

Keywords: Ramón del Valle-Inclán; "Testamento”; variants; textual criticism; genetic criticism.

Recepción: 20 de febrero de 2019; aceptación: 2 de mayo de 2019.

D.R. () 2020. Nueva Revista de Filología Hispánica Licencia Creative Commons Attribution-NonCommercial (CC BY-NC) 4.0 International 
El poema “Testamento" de Ramón del Valle-Inclán no fue publicado en vida de su autor*. Pese a ello, acaso sea el texto poético más conocido del escritor gallego. Su continuada aparición en estudios académicos y, especialmente, su presencia en infinidad de obras de divulgación, blogs y producciones audiovisuales han contribuido a ello. Tal vez su tono sarcástico haya propiciado este éxito popular. Pero quizá ese mismo carácter, su origen circunstancial u ocasional y su contenido mordaz, conectado estrechamente con la biografía del escritor, fueron los que provocaron asimismo que Valle-Inclán no lo incluyera en ninguno de sus poemarios, los cuales se caracterizaron por una cuidadosa elaboración, un planificado diseño y un decidido afán de trascendencia y perdurabilidad en el tiempo. Dado el directo y duro ataque al gremio periodístico que en el poema se vierte, la publicación en la prensa contemporánea parecía excluida de antemano. Por ello, el destinatario inicial de "Testamento" sería un círculo íntimo de familiares, amistades e integrantes de las tertulias del escritor. Con probabilidad, sería recitado por el autor ante un reducido auditorio y en algún caso circularía en copias manuscritas epistolares. No sorprende, pues, en principio, que las ediciones póstumas de "Testamento" recojan versiones diferentes del poema. Por lo demás, en la crítica valleinclanista se ha perpetuado una serie de errores que tiene su origen en malentendidos y lecturas incompletas o defectuosas de las primeras noticias sobre el poema o de los inaugurales estudios que lo dieron a conocer.

Ante la situación que se acaba de describir, este artículo aspira a aclarar la historia textual de "Testamento" presentando todos los testimonios de la tradición directa del texto de los que tengo noticia con información revisada y actualizada. Entre estos testimonios, se edita el primer impreso del poema, versión desconocida hasta la fecha en el ámbito académico, aparecida en la revista Mirador de Barcelona en 1937. Paralelamente, se intentará probar la veracidad de las siguientes afirmaciones: las ediciones póstumas no editan un texto definitivo; el poema no se redactó tres días antes de morir su autor; "Testamento" no fue publicado por primera vez por la periodista Josefina Carabias (tampoco por Ramón Gómez de la Serna en su tempra-

* Este trabajo se enmarca en las labores del Proyecto de Investigación FFl2015-63673-P "El retrato literario en el mundo hispánico (siglos XviIIXXI)", financiado por el Ministerio de Economía y Competitividad del Gobierno de España. 
na biografía); por último, los testimonios editados por Ramón Gómez de la Serna y Gaspar Gómez de la Serna son distintos, aunque ambos compartan apellido. Todas estas aserciones refutan algunas ideas muy extendidas en numerosos estudios sobre la obra del autor gallego.

\section{Relación de testimonios del poema “Testamento"}

\section{Testimonios manuscritos}

Ms. Índice ${ }^{1}$. En 1954, en los números 74/75 de la revista Índice de Artes y Letras, se publicó una sección titulada "Valle-Inclán en ocho páginas" que llevaba la indicación "con fotografías, autógrafos y textos inéditos, especiales para ÍNDICE". Efectivamente, el número incluye una novedosa e interesante documentación, entre la cual destaca la reproducción fotográfica de algunas cuartillas autógrafas pertenecientes a borradores de trabajo de obras inacabadas o descartadas ${ }^{2}$. Estos materiales y otros de diverso tipo procedían del archivo de Carlos del ValleInclán, hijo del escritor y custodio del legado. Así, por ejemplo, se reproduce un escrito en prosa titulado "A los liberales", una acotación de la primera escena de la obra teatral "El beato Estrellín" y, en la página 24 dentro del mismo recuadro, a la izquierda, una cuartilla con el fragmento de un borrador del poema "Réquiem", y a la derecha, una cuartilla con otro poema titulado "Testamento" ". Una nota anónima precisa el origen de ambas composiciones:

En octubre de 1932, Valle-Inclán enfermó tan gravemente, que un periodista le ofreció a la portera de la casa en que vivía cinco duros si le comunicaba antes que a nadie la noticia de su muerte. Don Ramón se enteró de este hecho y escribió al mismo tiempo que estos versos y en las mismas cuartillas los que se reprodu-

1 Utilizo las siglas Índice, GS y $C$ para estos tres testimonios del poema siguiendo el camino abierto por Javier Serrano, quien edita tres versiones de "Testamento" en el volumen Articulos completos y otras páginas olvidadas (VAlle-InClán 1987, pp. 421-423).

${ }^{2}$ Se ofrece un estudio de esta revista cultural y de opinión en Molina Cantero 1988.

3 También se reproduce un autógrafo de una tarjeta dirigida a Azorín y un breve fragmento del final del poema "Era el postrer momento", que se transcribe completo. 
cen en otro lugar de este número con el título de "Testamento" (Índice, p. 24).

"Réquiem" fue publicado en la revista Blanco y Negro el 30 de octubre de 1932. Teniendo en cuenta que la cuartilla que contiene este poema lleva el membrete "El Presidente del Ateneo de Madrid", el anónimo editor de la Obra completa en Espasa indica de forma tajante: "no hay duda ninguna de que fue compuesto en 1932" (Valle-Inclán 2002, t. 2, p. 2443), y documenta una enfermedad grave del autor gallego en mayo de ese año. 1932 podría ser, pues, la fecha de la primera versión del texto, si se acepta la génesis del poema que se propone en Índice (posiblemente brindada por Carlos del Valle-Inclán) o el argumento del membrete, pero siempre se trataría de una datación hipotética. Habría que precisar que la composición de Índice y las explicaciones que proporciona la revista hacen pensar en que se reproduce recto y verso de la misma cuartilla, pero puede que esto no sea así. E incluso siéndolo, no tiene por qué corresponder exactamente el momento de la redacción de los dos poemas. Tampoco se puede precisar con seguridad que este testimonio fuera una versión completa del poema con sólo tres estrofas, aunque ciertamente lo parece, ya que el texto podría continuar en otra cuartilla que no ha sido fotografiada ${ }^{4}$.

La imagen del autógrafo de Índice con sus tres serventesios ha sido reproducida en innumerables ocasiones desde 1954. En un artículo de 2012, en el que se presentaban los manuscritos conservados en el archivo familiar Valle-Inclán Alsina, Margarita Santos Zas incluyó en su anexo una fotografía en blanco y negro de la misma cuartilla editada en Índice procedente de ese legado (lámina 2, p. 169). La mayor calidad de la imagen me permite advertir que este testimonio es un borrador de trabajo y no un texto copiado en limpio, como parecía en las numerosas reproducciones anteriores ${ }^{5}$. Se observan dos fases o campañas

${ }^{4}$ Que un texto breve se extienda por varias cuartillas es práctica habitual en los borradores de este autor, ya que uno de sus rasgos caligráficos más distintivos es el uso de un tamaño de letra muy grande y el poco aprovechamiento del espacio material de la hoja, lo que le fuerza a la utilización de muchas cuartillas en sus documentos redaccionales.

${ }^{5}$ Lo que contradice afirmaciones de algunos estudios que mencionan el poema: "Sin ninguna enmienda ni tachadura, con letra apretada y vacilante, parecen escritas de un solo aliento, con la forma expresiva dominada y sapiente" (Hormigón 1987, p. 239). 
de redacción: una primera en tinta, que corresponde a la legible en la edición de Índice, y una segunda revisión para la que parece que el escritor ha utilizado un lápiz que en la revista no se aprecia. Las reescrituras son básicamente tachaduras de sustitución y adiciones. El autógrafo de Índice se convierte así de forma inesperada en un documento de la fase redaccional del texto y no pre-editorial, como se pensaba. Ésta sería la transcripción provisional de tal autógrafo ${ }^{6}$ :

\section{Testamento}

Te dejo mi cadáver. Reportero

El dia que me lleven a enterrar $<$ la cueva $>$

Fumarás a mi costa un buen veguero,

Fe darás en la Rumba un buen yantar.

$<y$ a mi muerte te $\{$ fumas $\}$ una $\{$ breva $\}$

$\mathrm{x} \times \mathrm{x}$

Y luego de cenar $<$ te $>$ eon mi fiambre,

Adobado en tu prosa gacetil, $<$ sin gramatica $>$

Humeando el puro, satisfecha el hambre,

Me injuriara tu dicharacho vit.<lengua epigramatica>

$\mathrm{x} \times \mathrm{X}$

Fe dejo mi eadaver. Verme ingrato

Harto de mi carroña, ingenuamente

Dirás gustando del bicarbonato:

Que Don Miguel no muera de repente. //

Ms. PA. El 4 de febrero de 1933, Valle-Inclán escribe en Madrid una carta que dirige a Ramón Pérez de Ayala, para manifestar su malestar por las actuaciones de Gregorio Marañón en el contexto de su deseada, pero discutida, elección al cargo de director de la Academia de Bellas Artes de Roma. El autor se encuentra en esos momentos hospitalizado en el Sanatorio de la Cruz Roja a la espera de una segunda intervención quirúrgica. Para el puesto se habían sugerido diferentes candidatos; por ello, el literato cree que se utilizará como subterfugio la dilación: "Buscarán la solución retardando indefinidamente el nombramiento, con la espera de que yo me muera". Si el

6 Transcripción que se basa en una imagen en blanco y negro y que tendría que ser necesariamente contrastada con el autógrafo original al que no he tenido acceso. Símbolos utilizados: / / fin de cuartilla; <> adición; \{\} lectura hipotética. Los manuscritos del archivo familiar de Valle-Inclán se encuentran depositados en la Biblioteca Xeral de la Universidad de Santiago de Compostela. 
autógrafo del legado Valle-Inclán Alsina reproducido en Índi$c e$ fuera cronológicamente anterior a esta carta, algo que no se puede probar por ahora ${ }^{7}$, Valle-Inclán podría haber estado involucrado, en febrero de 1933, en un proceso de reescritura para adaptar el borrador arriba citado a este nuevo contexto vital. En todo caso, el creador gallego copia en su misiva una versión más extensa del poema, que consta de cinco estrofas y veinte versos. Define el texto como sólo "un fragmento" de "un testamento que es una obra maestra del sarcasmo", el cual piensa continuar con "diatribas a los memos de la filología, a los anotadores y glosadores, a los Américos que se nutren de las carroñas literarias". Lógicamente, el destinatario prioritario del poema ya no es únicamente el "reportero" amoral que se lucra con la muerte del escritor, al que se deja en testamento el cadáver, sino un receptor múltiple al que se dirige con el apóstrofe inicial "Caballeros". Tras una estrofa prologal en la que se asume la llegada inevitable de la muerte, en la segunda estrofa se amplían las "mandas" metafóricas de este testamento sarcástico (laurel-tabernero, palmas-vecina, oropel-loco de guardilla), para terminar el poema con tres estrofas que desarrollan el motivo del periodista dándose un banquete y fumándose un puro a costa del finado. La referencia a Unamuno, cuyo fallecimiento inesperado arruinaría la satisfecha sobremesa del reportero, cierra, como en Índice, la composición.

Estas tres estrofas ofrecen una versión distinta y alternativa de los mismos elementos presentes en el autógrafo publicado en 1954: el ataque al periodista que injuriará la memoria del escritor y de cuya muerte se beneficia, la mala calidad de su prosa, el banquete macabro, fumar el puro, el bicarbonato. Desaparecen la mención al restaurante La Rumba (quizá demasiado localista), el insulto directo al reportero ("verme ingrato", ya tachado en Índice, aunque no se aprecie en el facsímil) y la evocación desagradable de podredumbre presente en el sintagma "harto de mi carroña". No obstante, la intervención final del periodista en estilo directo es en este testimonio más coloquial o barriobajera y menos respetuosa con Miguel de Unamuno:

Índice Que Don Miguel no muera de repente

$P A \quad-i Q u e$ ahora no la diñe Don Miguel!

${ }^{7}$ La opción contraria es menos plausible, pero no se puede descartar. 
La carta que contiene el poema fue hallada en la colección "Rodríguez Porrero" de la Biblioteca de Bartolomé March, cuando ésta se encontraba en Madrid, pero en la actualidad está ilocalizable ${ }^{8}$. Fue transcrita por Garlitz (1995, p. 106) y por Fuente (2001, pp. 162-164); este último añade una reproducción fotográfica del epistolario, lamentablemente de baja calidad, sobre la que he realizado mi transcripción (Fuente 2001, pp. 173 y 180-181), la cual difiere en algunos elementos de las dos anteriores ${ }^{9}$. El testimonio es relevante en la historia textual de "Testamento" -se trata de un autógrafo y una copia en limpio cuya fecha de redacción puede establecerse con seguridad-, aunque su autor lo considere un borrador inacabado.

¡Caballeros, salud y buena suerte!

Da sus últimas luces mi candil, Ha colgado la mano de la Muerte, papeles en mi torre de Marfil. //

Le dejo al tabernero de la esquina para adornar su puerta, mi laurel. Mis palmas al balcón de una vecina, A un loco de guardilla, mi oropel.

$$
\mathrm{x}^{\mathrm{x}} \mathrm{x}
$$

Para ti mi cadáver, reportero.

Si humo las glorias de la vida son

Tú te fumas mi gloria en un veguero, $Y$ te comes mi herencia en un figón.

$$
\mathrm{x}^{\mathrm{x}} \mathrm{x}
$$

Y después de cenarte mi fiambre

Adobado en retórica vanal,

Humeando el puro, satisfecha el hambre,

Haces con mi mortaja carnaval.

$$
\mathrm{x}^{\mathrm{x}} \mathrm{x}
$$

$\mathrm{Y}$ al tirar la colilla, con el chato

A medio consumir en el mantel,

Dirás gustando de bicarbonato,

-iQue ahora no la diñe Don Miguel!

${ }^{8}$ Según me informa Fausto Roldán, director de la Biblioteca de la Fundación Bartolomé March, la misiva no formaba parte de los fondos trasladados desde Madrid a Palma de Mallorca.

${ }^{9}$ La transcripción ha sido revisada por Antonio Gago Rodó, quien en su momento pudo consultar el autógrafo y a quien agradezco su amable colaboración. 
Conociendo la forma de trabajo del creador gallego, es muy posible que existieran varios manuscritos de trabajo del poema, ninguno de ellos definitivo; pero lo que parece indudable es que el texto no fue redactado unos días antes de su muerte o el 2 de enero de 1936, como se ha dicho ${ }^{10}$. La documentación que tenemos sobre los últimos días del escritor en el sanatorio del doctor Villar Iglesias en Santiago de Compostela indica que en ese momento Valle-Inclán estaba demasiado enfermo como para poder escribir (Valle-Inclán Alsina 2016) y que, en todo caso, sus últimos esfuerzos se dedicaron a la redacción de la novela corta El trueno dorado ${ }^{11}$.

Valle-Inclán recitó uno de los borradores del poema a Josefina Carabias en una fecha indeterminada de 1933. La periodista utilizó este episodio autobiográfico como tema central de su necrológica aparecida en la revista Crónica de Madrid el 12 de enero de 1936, titulada "La intimidad del gran don Ramón, «Reportero, te dejo mi cadáver»”. Sitúa la escena tres escasos años antes de su deceso, en fechas anteriores a su nombramiento como director de la Academia de Roma, cuando fue a visitar a don Ramón, que estaba enfermo, para realizarle una encuesta para $L a$ Voz:

Precisamente estaba escribiendo una cosa que te va a gustar. Son unos verzoz que tú te encargaráz de publicar cuando yo me muera. -Pero don Ramón, ¿qué dice usted?...

-Lo que oyes. Llevo unos días malos. Estoy aburrido, triste, y me divierto pensando en la muerte. Tú no te haces cargo de la serie de tonterías que se van a escribir cuando yo me muera... Por zupuezto que organizaréis eso que se llama una encuesta. Y habrá qué ver las contestaciones... iQué cosas dirán aprovechándose de que yo ya no podré contestar! Pero, en fin, te voy a leer el verso.

Don Ramón despegó la cabeza de las almohadas, hizo una pausa en el continuo sobo de su barba, que ya era completamen-

10 Solamente Valle-Inclán podría haber hecho una última revisión del poema redactado con anterioridad.

11 Tras el fallecimiento del escritor, el diario El Sol publicará el 7 de enero de 1936 un texto titulado "La primera y última cuartilla de su obra póstuma”, con la transcripción de dos páginas de un manuscrito que se encontraba en el sanatorio cuando el autor murió. Posteriormente, La Voz del 10 de enero de 1936 difundirá las imágenes en el artículo "Las últimas cuartillas de Valle-Inclán”. Estas páginas corresponden a la novela corta $\mathrm{El}$ trueno dorado (JUAN Bolufer 2015). 
te blanca, y comenzó a leer. Nunca se me olvidará que los versos empezaban así:

Reportero, te dejo mi cadáver... (Carabias 1936, p. [10]).

Josefina Carabias se quedó tan desconcertada por la lectura que no se atrevió a coger la cuartilla, que el autor volvió a leer delante de un grupo de amigos:

Pero no me los dio [los versos], ni yo me atreví a pedírselos. Mi cariño hacia don Ramón estaba por encima de todos los éxitos periodísticos. Ahora lo siento, y no ciertamente por eso. Lo siento porque aquella cuartilla manuscrita, que decía cosas extraordinarias, hubiera sido un magnífico recuerdo de don Ramón del Valle Inclán (Carabias 1936, p. [10]).

Tras una breve semblanza del Valle-Inclán más familiar, la periodista se dirige a su hijo Carlos:

Tú, que ya eres un hombrecito, serás, sin duda, quien mire y repase los papeles escritos que ha dejado tu padre. Cuando tropieces con una cuartilla que comienza diciendo: Reportero, te dejo mi cadáver..., guárdamela. Es mía (Carabias 1936, p. [11]).

El hecho de que Josefina Carabias recuerde una sola cuartilla manuscrita y que identifique el comienzo del poema con el apóstrofe al reportero parece señalar que Valle-Inclán leyó una versión del borrador de Índice. Si fuera así, y nos fiáramos de la memoria de la periodista, su redacción sería anterior al 8 de marzo de 1933, fecha del nombramiento de Valle-Inclán como director de la Academia de Roma, en datas similares a las de la carta de Pérez de Ayala ${ }^{12}$.

Tras la lectura de estas citas, es evidente que el artículo de Carabias publicado en Crónica no edita el poema "Testamento", como se dice en numerosos estudios sobre Valle-Inclán que perpetúan otro error manifiesto. El origen de esta confusión puede residir simplemente en el título de la necrológica, el cual reco-

12 Sin embargo, conviene destacar que hay algunas contradicciones entre la situación temporal de la anécdota que se presenta en la necrológica -una encuesta para $L a$ Voz previa al nombramiento como director de la Academia- y una entrevista publicada el 9 de marzo de 1933 por la periodista a raíz de dicho nombramiento ("Hablando con Valle-Inclán, nuevo director de la Academia Española de Bellas Artes de Roma”), pues, según declara, tal entrevista fue su primer trabajo para La Voz (CARABias 1981, pp. 173 ss.). 
ge el verso inicial del poema, o quizá en la lectura defectuosa de una nota de la bibliografía de José Rubia Barcia (1960, p. 23, n. 80), texto que se repite en su colaboración para el influyente volumen colectivo Ramón del Valle-Inclán. An appraisal of his life and works (1968, p. 33, n. 100). Justo antes del listado de los testimonios del poema que se conocían en 1960, Rubia Barcia coloca una mención a la necrológica de Carabias. El hecho de que el error aparezca en los tan consultados compendios de Juan Antonio Hormigón, Valle-Inclán. Cronología. Escritos dispersos. Epistolario (1987, p. 239) y Valle-Inclán... Epistolario (2006, t. 3, p. 178), así como en la difundida biografía de Manuel Alberca y Cristóbal González, Valle-Inclán. La fiebre del estilo (2002, p. 278), ha provocado con bastante probabilidad su repetición en otros muchos estudios.

Tras el fallecimiento del escritor, se lanzaron variopintos proyectos de homenaje póstumo, la mayor parte de los cuales no pasó de la fase de propuesta bienintencionada. Una de las iniciativas más serias fue la de realizar una edición póstuma de obras de Valle-Inclán que podría recoger los inéditos que poseía la familia. Esta idea partió del Ayuntamiento de Madrid, que entonces gobernaba una gestora municipal, como recogen prácticamente todos los medios periodísticos madrileños ya para el 8 de enero de 1936. Desde Galicia, algunos admiradores del escritor consideraron que eran sus paisanos los que debían encargarse de la tarea al haberse frustrado el objetivo de donarle un pazo en vida ${ }^{13}$. El 10 de enero, la gestora madrileña invitó a participar en el proyecto a Manuel Machado, al Ateneo, al Lar Gallego y a la asociación Anaquiños da Terra ${ }^{14}$, mientras en Galicia se hacían también diversas propuestas de edición. Ninguna se llevó a cabo. En este proceso fallido ha de situarse una carta de Josefina Blanco a Manuel Machado, fechada el 25 de enero de $1936^{15}$ :

13 Como muestra, "Ejemplo para los Ayuntamientos gallegos. El de Madrid organizará un homenaje en memoria de Valle-Inclán”.

14 Por ejemplo, en "Vecinos sin concejales... El homenaje a la memoria de D. Ramón está en marcha".

${ }^{15}$ En el contexto del homenaje planeado por el Ayuntamiento de Madrid, Javier del Valle-Inclán Alsina (2016, p. 75) recogió esta misiva del epistolario de los hermanos Machado, editado por González Alonso. El volumen reproduce dos cartas más de Josefina Blanco a Manuel Machado relativas a dicho homenaje, fechadas, respectivamente, el 4 de febrero y el 5 de marzo de 1936 (González 1981, pp. 46-52). En esta última, Josefina 


\section{5-I-936}

Sr. D. Manuel Machado

Distinguido amigo: Desde hace días me mortifica una duda que solo a usted puedo confiar, y solo usted, con su fino espíritu, puede resolver. ¿Convendría publicar los versos: "Reportero te dejo mi cadáver"? El volumen del tomo apenas aumentará, pero la ironía despectiva que encierran, pudiera suscitar molestias desagradables. Al menos este es mi temor y a usted se lo confío. Más tarde, entre otras cosas inéditas como cartas, artículos, etc. podría incluirse eso. Ahora, en un libro de homenaje, ¿debe ir?

Busco en usted al amigo leal de siempre, al consejero autorizado, al artista de sensibilidad exquisita capaz de apreciar este matiz espiritual y su decisión de usted me parecerá inapelable.

Con el mayor afecto estrecha su mano

Josefina Blanco

Viuda de Valle-Inclán

(apud González 1981, p. 49; facsímil, p. 50).

Esta carta permite comprobar que un manuscrito del poema era conservado por la familia y que Josefina consideraba que el poema se encontraba en un estado pre-editorial. El primer verso de "Testamento" que cita, "Reportero te dejo mi cadáver", coincide con el mencionado por Josefina Carabias y se acerca más al testimonio de Índice ("Te dejo mi cadáver. Reportero") que al de la carta dirigida a Pérez de Ayala ("¡Caballeros, salud y buena suerte!”). O Josefina Blanco manejaba entonces una copia del poema distinta a la conservada en los dos autógrafos descritos o cita el verso sin mayor precisión.

\section{Testimonios impresos}

M. El 15 de abril de 1937, el semanario Mirador de Barcelona publicó un texto poético en la sección "Les Lletres", que tituló "Testamento improvisado en una tarde angustiosa por don Ramón del Valle-Inclán" e incluyó dentro del artículo anónimo "Un poema inèdit de Valle-Inclán"16, ilustrado con un retrato

pide a Machado que le devuelva el original de El trueno dorado, en vista de que el proyecto se ha paralizado.

${ }_{16}$ El semanario Mirador (Barcelona, 1929-1937) se considera una de las publicaciones catalanas más relevantes de la época. En sus páginas colaboraron los principales intelectuales del momento. Véase Singla Casellas 2006 para un estudio muy completo de la revista. 
del autor gallego Ángel Carretero. Se trata de un testimonio ignorado del poema, que ha permanecido olvidado en las páginas de esta revista en lengua catalana ${ }^{17}$ y que se convierte así en la primera publicación póstuma de "Testamento" ${ }^{18}$. En el artículo sin firma, se comunica que el texto procede de una copia de Josefina Blanco, que ella había proporcionado a Luis Ruiz Contreras junto con el permiso para su edición:

En l'article de Josefina Carabias es feia referència a un poema que la mort de Valle-Inclan havia deixat inèdit. Res més no haviem sabut d'aquesta composició inèdita de l'autor d'El ruedo ibérico.

Trobant-se actualment a Barcelona Luis Ruiz Contreras, hem volgut entrevistar-nos amb ell per tal de saber què havia de cert sobre l'existència del poema inédit de Ramón del Valle-Inclan. L'autor de Medio siglo de teatro infructuoso i de les Memorias de un desmemoriado ens ha confirmat la seva existència; la composició de Valle-Inclán fou lliurada a Ruiz Contreras per Josefina Blanco i fins a la data havia romàs inconeguda del públic.

Luis Ruiz Contreras ha tingut la gentilesa de lliurar-nos l'esmentat poema, així com una prosa seva que publicarem la vinent setmana ${ }^{19}$. Autoritzat per Josefina Blanco per a fer de la composició de Ramón del Valle-Inclán l'ús que cregués més convenient, el vell escriptor Ruiz Contreras ens ha fet el gran honor de permetre que sigui MIRADOR la primera publicació que per primera vegada l'ofereixi al públic (Mirador, p. 6).

Ruiz Contreras había mantenido una larga amistad con el escritor gallego, al que había conocido en Madrid a finales del siglo XIX ${ }^{20}$. Había realizado trámites para publicar la obra de Valle-Inclán en los últimos años de su vida, como una edición de lujo de las Sonatas y una antología con el librero Bergua, de

17 Un año antes, el semanario había publicado a raíz de la muerte del escritor un artículo necrológico anónimo ("Valle-Inclán") y una interesante necrológica de Josep M. Sagarra, que estudia Sotelo Vázquez (2008, pp. 317-318).

${ }^{18}$ Este testimonio fue localizado durante una investigación sobre las necrológicas de Valle-Inclán (JuAN Bolufer 2018), que partió de un listado bibliográfico proporcionado generosamente por el profesor Javier Serrano Alonso, a quien agradezco la información sobre la revista Mirador que me llevó a este testimonio desconocido y, por lo tanto, a su estudio.

19 Efectivamente, Ruiz Contreras publicará en la revista el artículo titulado "El banc del «si no fos»", también en la sección "Les Lletres".

${ }^{20}$ Se estudia la relación de Ruiz Contreras con Ramón del Valle-Inclán y Josefina Blanco en Rubio y DeAño 2011. 
la que resultaría la colección póstuma Flores de almendro. Asimismo, había impulsado varias iniciativas que ayudaran a mejorar la situación económica del autor. Tras su muerte, mantuvo el contacto con Josefina Blanco, según documenta el epistolario conservado entre ambos. Josefina se apoyó en el consejo de Ruiz Contreras como experto conocedor del mundo editorial, pero también como amigo leal ante las graves dificultades que pasó la familia Valle-Inclán durante la contienda bélica y la inmediata posguerra. Ruiz Contreras pudo disponer de una copia del poema realizada por Josefina Blanco a partir de un manuscrito de Valle-Inclán, tarea que hacía con frecuencia cuando los textos estaban ya en fase pre-editorial, o bien pudo realizar la copia él mismo. Éste es el poema en la versión de $M$ :

Te dejo mi cadáver, reportero.

El día que me lleven a enterrar,

fumarás a mi costa un buen veguero;

te darás en "La Rumba" un buen yantar.

Y después de cenarte mi fiambre adobado en retórica banal, humeando el puro y satisfecha el hambre le rifas mi mortaja a un carnaval.

Y al tirar la colilla, con el chato a medio consumir en el mantel, dirás, gustando del bicarbonato: ¿Que ahora no la diñe don Miguel...!

Para ti mi cadáver, reportero, mis anécdotas todas para ti. ¡Le sacas a mi entierro más dinero que en mi vida mortal yo nunca vi! (Si humo las glorias de la vida son, tú te fumas mi gloria en un veguero y te das un banquete en un figón.)

Caballeros: salud y buena suerte; da sus últimas luces mi candil; ¡ha colgado la mano de la Muerte, papeles en mi torre de marfil!

Le dejo al tabernero de la esquina, para adornar su puerta, mi laurel; 
mis palmas al balcón de una vecina, y a una máscara loca, mi oropel.

Como se puede observar, $M$ es la versión más extensa de todos los testimonios de "Testamento", ya que se compone de 6 estrofas y 37 versos. Su serventesio inicial corresponde a la estrofa inaugural de la primera fase de redacción del manuscrito Índice, mientras que la segunda y la tercera estrofa, aunque mantienen el orden y la estructura temática básica del autógrafo, presentan variantes estilísticas significativas, que a su vez remiten a la versión de $P A$, en la que estas estrofas encuentran su lugar al final del poema. El número mayor de versos se origina por una adición en el cuarto serventesio. Éste conserva el primer verso de la tercera estrofa de la carta "Para ti mi cadáver, reportero" y presenta como novedad en su continuación el motivo del legendario anecdotario valleinclaniano, del que asimismo se lucra el reportero. A estos cuatro versos se añaden tres versos entre paréntesis que constituyen una especie de inciso o aclaración de su contenido, versos que ya formaban parte de la tercera estrofa de $P A^{21}$. El serventesio se convierte así en una estrofa de 7 versos con la rima ABABCAC.

\begin{tabular}{ll}
\hline$P A$ & $M$ \\
\hline Para ti mi cadáver, reportero. & Para ti mi cadáver, reportero, \\
Si humo las glorias de la vida son & mis anécdotas todas para ti. \\
Tú te fumas mi gloria en un veguero, & ¡Le sacas a mi entierro más dinero \\
Y te comes mi herencia en un figón. & $\begin{array}{l}\text { que en mi vida mortal yo nunca vi! } \\
\text { (Si humo las glorias de la vida son, } \\
\text { tú te fumas mi gloria en un veguero } \\
\text { y te das un banquete en un figón.) }\end{array}$ \\
\hline
\end{tabular}

Esta adición y recolocación del inciso resulta extraña en un poema tan regular desde el punto de vista de sus rimas en los dos autógrafos conservados. En ambos manuscritos, el escritor gallego coloca tras cada serventesio tres cruces con la intención de indicar con claridad la separación estrófica. De igual forma, esta estrofa irregular no aparece con frecuencia en la poesía del autor, por lo que conviene subrayar su presencia como posible indicio de que la transcripción fue realizada por perso-

21 Con variante: $P A Y$ te comes mi herencia en un figón; $M y$ te das un banquete en un figón. 
na ajena que quizá haya manejado un borrador de trabajo que incluía reescrituras, como se ha visto en el manuscrito de Indi$c e$. La hipótesis que considero más plausible es que Josefina o Ruiz Contreras utilizaron un manuscrito con una reescritura de los tres versos finales de la cuarta estrofa, presentados en el borrador como alternativas posibles ${ }^{22}$ o como reescrituras, que su editor transcribió en su edición como textos sucesivos, procedimiento que aumenta el número de versos de la estrofa. Sin embargo, si los vemos como opciones posibles, quizá una de ellas descartada en una segunda fase de redacción, se obtienen dos estrofas totalmente regulares:

Para ti mi cadáver, reportero

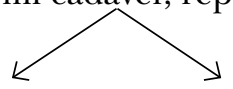

Si humo las glorias de la vida son mis anécdotas todas para ti. Tú te fumas mi gloria en un veguero, ¡iLe sacas a mi entierro más dinero Y te comes mi herencia en un figón. que en mi vida mortal yo nunca vi!

Por último, en $M$ se produce una alteración del orden con respecto a $P A$, pues se colocan al final del poema las dos primeras estrofas de esta última versión ("Caballeros, salud y buena suerte" y "Le dejo al tabernero de la esquina"), con variante en el verso conclusivo:

$P A \quad$ A un loco de guardilla, mi oropel.

$M \quad$ y a una máscara loca, mi oropel.

La versión $M$ quizá resulte más comprensible para un lector actual. "Loco de guardilla" podría tener el significado de "loco de atar", o bien remitir a Miguel de Cervantes o a un personaje similar de escritor pobre, risueño y genial, rasgos de caracterización del protagonista de la famosa zarzuela de Narciso Serra, con música de Manuel Fernández Caballero, El loco de la guardilla ${ }^{23}$.

22 Alternative non résolue, en términos de la crítica genética.

23 “ ¡Hidalgo de capa rota / y morador de guardilla / que por falta de golilla / la ropilla se descota! / ¿Cómo tras tanto cilicio / la sangre no se le fríe? / ¿Cómo ríe? Y si se ríe, / ¿cómo ríe y tiene juicio? / El casero, que no es lerdo, / quiere que le satisfaga, / y viendo que no le paga / sostiene que no está cuerdo: / el bachiller Bobadilla, / el que habita con su ama / el cuarto bajo, le llama / «El loco de la Guardilla»" (SERRA 1888, p. 17); "pobre, y sin 
Este cambio estructural en la combinación de las estrofas podría deberse a la mano del editor o del autor. Creo que es más probable el primer supuesto, ya que la referencia a Unamuno cierra los dos autógrafos conocidos y constituye un final sumamente efectivo del poema que no está en $M$. Asimismo, los versos con el apóstrofe a los caballeros y la constatación de la llegada próxima de la muerte parecen tener un carácter prologal que no encaja con su colocación en la penúltima estrofa en $M$. Es posible que el borrador proporcionado por Josefina Blanco a Ruiz Contreras se extendiera por varias cuartillas y el editor tomara la decisión de ordenar el poema de esta forma, y no como recoge Valle-Inclán en $P A$.

GS. En 1944 Ramón Gómez de la Serna publicó, en el capítulo XXI de su personal y muy difundida biografía del autor gallego titulada Don Ramón María del Valle-Inclán, una versión diferente del poema "Testamento" que consta de dieciocho versos ${ }^{24}$. La copia, según declaración del biógrafo, provenía del entorno familiar. El contexto vital de la creación del texto que se presenta difiere del mencionado en los anteriores testimonios, tanto en la explicación del origen de "Testamento" como en la hipotética fecha de redacción. Estando Valle-Inclán en Madrid de vuelta de Roma, en unas vacaciones previas a su último retorno (Gómez de la Serna 1944, p. 198), habría sido asaltado por un periodista poco respetuoso:

Hacía días le había preguntado uno de ellos [periodistas malos y cínicos]:

-¿Cuándo la diñamos don Ramón?

Parece que, impresionado por el desacato de aquellas insolencias, según contó a sus hijos, escribió estos versos, que ellos me han dado y que estaban dedicados a esos imprudentes y malos reporteros (Gómez de la Serna 1944, p. 200).

empleo y viejo, / dime a componer un libro, / y con gracia, o desgraciado, / yo a solas con él me río: / por verme risueño y pobre / todos loco me han creído" (SERra 1888, p. 25); "la patria ingrata no vio / que Cervantes no cenó / cuando concluyó el Quijotè" (SERRa 1888, p. 31). El libreto se basaba en un cuento de Juan Eugenio Hartzenbusch.

${ }^{24} \mathrm{El}$ testimonio es muy conocido y se reproduce más adelante en este artículo con GGS. Un estudio de esta biografía en el contexto literario español y europeo contemporáneo, así como en la producción biográfica de su autor, puede leerse en Serrano Asenjo 2002. 
La información proporcionada por los hijos del escritor a Ramón, ya en la posguerra, no concuerda con las noticias del documento de la carta de Pérez de Ayala, al cual habría que otorgar un mayor valor testimonial por tratarse de un autógrafo que transmite la voz propia del autor y no del recuerdo de los que entonces eran unos adolescentes. Aunque Ramón no es muy preciso en la datación, hipotéticamente se podría deducir que el incidente con el periodista habría tenido lugar entre agosto de 1933 y marzo de 1934.

RubioJiménez (2015) ha examinado el recorrido de lo anecdótico a lo sustancial, "de la impresión al intento de aprehender lo esencial de la personalidad del retratado" (p. 158) que fue realizado por Gómez de la Serna desde sus primeras siluetas y retratos de Valle-Inclán hasta llegar al ensayo biográfico de 1944. Para el propósito de este artículo, interesa particularmente destacar su peculiar forma de trabajo. Gómez de la Serna "operaba a base de recuerdos de su trato con don Ramón, refrescados con la contemplación de retratos del biografiado y releyendo escritos suyos o sobre él glosando su singular personalidad" (Rubio 2015, p. 152), mientras ejercitaba un proceso de videncia o adivinación sucesiva del biografiado. Buena prueba de este proceder es la carta que Rubio edita procedente del Fondo Daniel Devoto-María Beatriz del Valle-Inclán, depositado en la Fundación Lázaro Galdiano:

Ramón Gómez de la Serna

Buenos Aires

Victoria 1970

Tel. 47.4775

Mi querida Mariquiña:

Muchas gracias por sus referencias a esos versos admirables de su padre, nuestro gran Don Ramón.

Está bien que consulte con Jaime por si pudieran completarse, pues tienen la inmensa amargura que merecía la España literaria que no se portó como debía con él y logró que se fuera más pronto de lo que debía haberse marchado.

Estoy frente a un caballete lleno de retratos de él, procreando mi sonambúlica obra de admiración y justicierismo.

Con muchos recuerdos a su esposo es su muy devoto

Ramón

Muchos recuerdos de Luisita.

El recorte que le envío está un poco mal recortado pero se puede leer

(apud Rubio 2015, pp. 181-182). 
Ramón, que se encuentra inmerso en la redacción de la biografía, agradece a la hija de Valle-Inclán sus referencias sobre "unos versos" que creo que sólo pueden ser, por el contenido de la carta y por el prólogo del libro, "Testamento". El poema se prestaba muy bien no sólo al procedimiento adivinatorio de exploración de imágenes sucesivas, sino al propósito declarado de su autor de hacer una "obra de admiración y justicierismo" que anuncia en la misiva (apud Rubio 2015, p. 181) y que es bien visible desde las primeras oraciones de la biografía. "Para mí Valle-Inclán es un ejemplo excelso como prototipo de escritor digno" (Gómez de la Serna 1944, p. 10), acribillado por falsas y verdaderas anécdotas, señala Ramón en la introducción de su biografía, que presenta como "el noli me tangere para los que creen que se pueden equiparar con él, sin tener en cuenta que no sólo es un estilo, sino un alma noble" (Gómez de la Serna 1944, p. 11).

Este proyecto biográfico de Gómez de la Serna ha de enmarcarse necesariamente en el contexto de la recepción del último Valle-Inclán, el esperpéntico, y del debate generado en las necrológicas del autor, cuando la crítica literaria de ideología conservadora sólo reconoció la importancia de la obra del escritor gallego en un plano formal y estilístico, pero denigró su persona y denostó su figura pública, al tiempo que los sectores más progresistas de la izquierda, desde la moderada a la radical, y los escritores vanguardistas vieron en el creador asimismo un modelo de escritor crítico, responsable y comprometido con la sociedad de su tiempo (Juan Bolufer 2018). Ramón presenta a Valle-Inclán desde su "furor ético" como modelo digno de ser imitado ${ }^{25}$ : "Con que se desprenda esa lección calmante y animadora de la proyección de esta vida, la biografía habrá logrado su arquitectura de altar y su gloria vindicadora" (Gómez de la Serna 1944, p. 15). El poema "Testamento" tiene para Ramón, como dice en la epístola, "la inmensa amargura que merecía la España literaria que no se portó como debía con él" (apud Rubio 2015, p. 181), y por eso aludirá al texto poético, sin citarlo expresamente y parafraseando su contenido, ya en la segunda oración del prólogo de su biografía: "Pero es muy de este tiem-

25 En palabras de SERrano Asenjo (2005, p. 178), Ramón se proyecta e identifica con su tocayo y practica un autobiografismo por persona interpuesta: "pocas veces llega tan allá Ramón a la hora de utilizar a otro creador para mostrar sus obsesiones más hondas”. 
po el vivir de las anécdotas del gran hombre, los mismos que fueron los primeros gusanos que comenzaron la vitanda tarea de comérsele" (Gómez de la Serna 1944, p. 9). El ejercicio biográfico de Gómez de la Serna, del que se pretende extraer una lección de vida, se planteará así como respuesta a los ataques vertidos por los reporteros carroñeros, con el poema "Testamento" como subtexto.

Gómez de la Serna reproduce en su transcripción dos de los serventesios y parte del tercero del testimonio de $P A$. El resto del poema editado, que en su parte final recoge elementos de Índice ${ }^{26}$, es muy irregular en sus rimas y algo incoherente, o incluso se podría calificar de fallido en su desarrollo, por lo que quizá se podría sospechar que responde tal vez a un borrador muy primerizo o lleno de reescrituras, o con mayor probabilidad a una versión memorizada total o parcialmente. Tal vez por ello Ramón solicite a Mariquiña en la carta reproducida que pida mayor información a su hermano Jaime para completar el poema. La lectura de su última estrofa provoca la impresión de ser un texto híbrido, que quizá no haya existido en esa peculiar forma.

El poema "Testamento", reproducido en un artículo de Isabel de Ambía dos años después, publicado en Cuadernos de Literatura Contemporánea, es el mismo que el de GS, como la propia autora señala, por lo que resulta irrelevante en este repaso de los testimonios del poema (Ambía 1946, p. 484).

C. En 1950, Camilo José Cela vuelve a editar el poema en la revista Clavileño a partir de la que considera versión definitiva de "Testamento", así titulada, frente a las reproducidas por Ramón y Ambía. Sin aportar más datos, afirma que el texto fue escrito el 2 de enero de $1936^{27}$. Sin embargo, Cela no desvela sus fuentes y edita con alguna errata ${ }^{28}$ una transcripción del poema

${ }^{26}$ Es el único testimonio de los conservados que recoge, por ejemplo, las lecciones presentes en Índice "en tu prosa gacetil" o "harto de mi carroña, ingenuamente".

${ }^{27}$ La edición de Índice rebate esta datación: "Es inexacto, pues, que estos últimos versos los escribiera días antes de su muerte, como se ha dicho en algún sitio" (p. 24).

28 "Dicharado [dicharacho], gustando [del o de] bicarbonato". Es posible que exista asimismo una errata en "que en mi vida mortal [yo] nunca vi” (endecasílabo). 
de 24 versos, numerados uno a uno ${ }^{29}$, muy cercana a $M$, pero no idéntica, y elimina con acierto, desde mi punto de vista, el molesto inciso de tres versos:

M C

Te dejo mi cadáver, reportero.

El día que me lleven a enterrar,

fumarás a mi costa un buen veguero;

te darás en "La Rumba” un buen [yantar.
1. Te dejo mi cadáver, reportero.

2. El día que me lleven a enterrar,

3. fumarás a mi costa un buen

[veguero,

4. te darás en la "Rumba" un buen

[yantar.

Y después de cenarte mi fiambre

5. Y después de cenar con mi

adobado en retórica banal,

[fiambre,

humeando el puro y satisfecha el

6. adobado en retórica sutil,

[hambre

le rifas mi mortaja a un carnaval.

7. humeando el puro, satisfecha el

8. me injuriará tu dicharado vil.

[hambre,

Y al tirar la colilla, con el chato

a medio consumir en el mantel,

9. Y al dejar la colilla con el chato,

10. a medio consumir, sobre el

dirás, gustando del bicarbonato:

11. dirás, gustando bicarbonato,

[mantel,

¿Que ahora no la diñe don Miguel...!

12. "QQue no la diñe ahora don

[Miguel!”.

Para ti mi cadáver, reportero, mis anécdotas todas para ti.

13. Para ti mi cadáver, reportero, 14. mis anécdotas, ¡todas para ti! ¡Le sacas a mi entierro más dinero 15. Le sacas a mi entierro más dinero que en mi vida mortal yo nunca vi! (Si humo las glorias de la vida son, 16. que en mi vida mortal nunca vi. tú te fumas mi gloria en un veguero y te das un banquete en un figón.)

Caballeros: salud y buena suerte; da sus últimas luces mi candil;

17. Caballeros, salud y buena suerte.

18. Da sus últimas luces mi candil.

¡ha colgado la mano de la Muerte, papeles en mi torre de marfil!

19. Ha colgado la mano de la muerte

20. papeles en mi torre de marfil.

Le dejo al tabernero de la esquina, para adornar su puerta, mi laurel; mis palmas al balcón de una vecina,

y a una máscara loca, mi oropel.

21. Le dejo al tabernero de la esquina, 22. para adornar su puerta, mi laurel.

23. Mis palmas, al balcón de una

[vecina,

24. y a una máscara loca, el oropel.

${ }^{29}$ Esta práctica tan extraña puede deberse a motivos de composición tipográfica. La estrechez de la columna en la composición de la página de la revista no permite reproducir el verso completo en la misma línea. 
Las otras diferencias, como se puede comprobar en el cotejo, constituyen ligeras variantes estilísticas ${ }^{30}$, probablemente de autor, y cambios en la puntuación, los cuales pueden deberse a alteraciones de los dos editores ${ }^{31}$. Ha de llamarse la atención sobre la inclusión del verso: "me injuriará tu dicharado vil" -errata por dicharacho- en esta versión, ya que es el único de los testimonios impresos que incluye esta posibilidad, presente en el testimonio de Índice.

GGS. En 1958, Gaspar Gómez de la Serna, en el prólogo a las Obras escogidas de Valle-Inclán de la editorial Aguilar, reproduce otra versión de "Testamento" con cinco serventesios, que vuelve a editar en su libro Entrerramones y otros ensayos en 1969. Me interesa especialmente destacar la presencia de las notas que acompañan la edición del poema en ambos tomos:

Esta versión del famoso "Testamento" de don Ramón es la primera que se saca directamente de las cuartillas originales en las que quedan todavía algunas variantes de interés (Gómez de la Serna 1958, p. 11, n. 1).

Esta versión del famoso "Testamento" de don Ramón fue la primera que se sacó directamente de las cuartillas originales, facilitadas por Carlos del Valle-Inclán, el hijo del escritor, en las que quedan todavía algunas variantes de interés (Gómez de la Serna 1969, p. 9, n. 2).

Parece evidente, en primer lugar, que Gaspar Gómez de la Serna no conocía la publicación de Mirador. También es indiscutible que tenía una relación estrecha con Carlos del ValleInclán, al que denomina "mi buen amigo" (Gómez de la Serna 1969 , p. 42), puesto que ningún valleinclanista en esa épo-

30 MY después de cenarte mi fiambre $M$ adobado en retórica banal, $M$ le rifas mi mortaja a un carnaval. $M Y$ al tirar la colilla, con el chato $M$ ¡Que ahora no la diñe don Miguel...! C “QQue no la diñe ahora don Miguel!”.

31 Algunas variantes podrían explicarse como medio para conseguir la regularidad métrica del endecasílabo: $M$ humeando el puro y satisfecha el hambre; $C$ humeando el puro, satisfecha el hambre, 
ca había accedido al archivo manuscrito ni a la biblioteca del autor $^{32}$.

En segundo lugar, el texto es semejante al que se reproduce en la carta de Valle-Inclán a Pérez de Ayala, aunque con tres variantes estilísticas sustanciales que podemos considerar, con alta probabilidad, variantes de autor:

PA A un loco de guardilla,
[mi oropel.
PA Y te comes mi herencia
[en un figón.
PA Haces con mi mortaja

[carnaval.
GGS a una máscara loca,

[mi oropel. $G G S$ y te das un banquete [en un figón. $G G S$ me rifas mi mortaja [en carnaval.

Si en primer lugar se tienen en cuenta las declaraciones del editor en las que comunica que está manejando un borrador con variantes; si en segundo, se advierte que el testimonio GGS proviene de Carlos del Valle-Inclán y, por último, si se observa que el testimonio que el hijo del escritor proporcionó a Índice cuatro años antes es distinto de $M$, se podría deducir que aun cuando los otros editores no lo hagan explícito, y puesto que los textos proceden sin excepción del fondo familiar, todos ellos están manejando borradores de trabajo con reescrituras.

El testimonio de Ramón Gómez de la Serna (GS), por su estructura y características básicas, formaría parte de la misma familia de testimonios que $P A$ y $G G S$-según puede verse en el cuadro de la siguiente página-, aunque presente un grado mayor de desviación, quizá por contaminación con un testimonio cercano al manuscrito Índice, ya que, como se ha dicho, pudo ser transmitido parcialmente por la memoria.

Sin el espacio necesario para el comentario o discusión de cada una de las variantes, se imponen en este momento una serie de conclusiones. Se ha podido constatar que la historia textual del poema presenta una gran complejidad derivada de una tradición mixta y paralela. En la actualidad, se conocen dos testimonios autógrafos de "Testamento" (Índice y $P A$; el primero quizá incompleto) y cuatro impresos póstumos $(M, G S, C, G G S)$, procedentes de copias del archivo familiar, proporcionadas a

32 En Entrerramones se incluye una lista de las obras históricas que el escritor tenía en su biblioteca personal, inventario desconocido que le había proporcionado su hijo el 3 de agosto de 1952. 


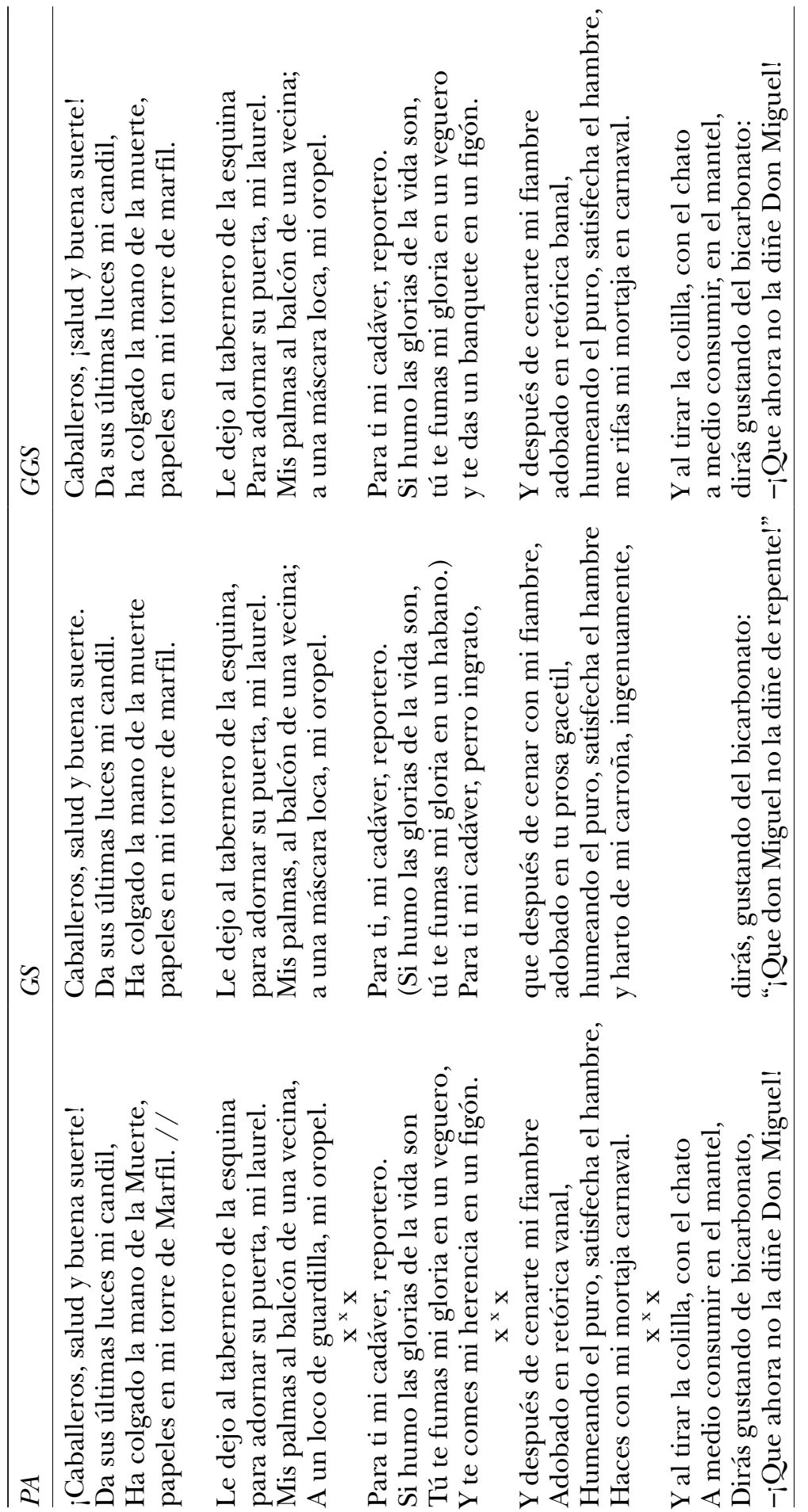

Nueva Revista de Filología Hispánica (NRFH), LXVIII, 2020, núm. 2, 695-722

ISSN 0185-0121; e-ISSN 2448-6558; DOI: 10.24201/nrfh.v68i2.3654 
sus editores por Josefina Blanco, María Beatriz del Valle-Inclán ${ }^{33}$ y Carlos del Valle-Inclán ${ }^{34}$. Ninguno de estos testimonios podría considerarse definitivo o pre-editorial por no recoger una versión del texto elaborada y autorizada por el escritor (la última mano o la última voluntad), ya que es posible que el poema nunca llegara a tal estado de elaboración.

Tras el estudio de la historia de la tradición del texto, se puede conjeturar que tanto los autógrafos como los impresos serían en realidad borradores de trabajo, con sus previsibles reescrituras, vacilaciones o tanteos, incluido Índice, que se ha revelado como ante-texto tras publicarse en fecha reciente una reproducción fotográfica de mayor calidad. Los testimonios impresos que se han relacionado serían entonces copias realizadas por un editor de manuscritos todavía en fase redaccional que formarían parte del dosier de génesis del poema, no transcripciones de documentos pre-editoriales o editoriales. Los materiales descritos nos permitirían observar diferentes estados en el sentido en el que se definen en la crítica genética. Los editores tuvieron que manejar borradores similares a los dos autógrafos conservados, pero distintos, los cuales podrían ser localizados en el futuro en el archivo familiar, a menos que se hayan perdido. No podríamos considerar "Testamento" un texto cerrado, como se ha hecho hasta ahora. Por ello, las diferencias entre los testimonios impresos (supresiones, adiciones y transformaciones) quizá se deban en su mayor parte a este origen y a la transcripción de variantes de autor, tanteos o alternativas posibles. Llevan el sello estilístico de Valle-Inclán, y las lecciones de los dos autógrafos confirman parcialmente dicha paternidad.

Sin embargo, los testimonios impresos parecen implicar un trabajo de edición o arreglo de tales materiales. Los diferentes editores han transcrito un texto que presentan como definitivo, obviando las reescrituras fruto de variantes de lectura sustanciales, como señala con suma claridad Gaspar Gómez de la Serna en sus notas. Ninguno realiza una transcripción diplomática del poema. No se puede descartar por ello la manipulación de los editores, quienes probablemente hayan tenido que tomar decisiones en su labor de copia o, por el contrario, hayan hecho una lectura errónea de los manuscritos (si éstos

33 Pudo haberse recogido a partir de la memorización del poema.

${ }^{34}$ Con la excepción de $C$, cuya procedencia no se indica. 
no estaban especialmente limpios). Así parece probarlo, si comparamos todos los testimonios, el inciso de tres versos que se ha analizado anteriormente, pues podría ser, en un borrador desconocido, una alternativa sin resolver o una variante de autor inmediata, que en $M$ se decide transcribir y en GGS suprimir, por considerar que proviene de una fase redaccional anterior o de menor calidad literaria. Parece asimismo que los editores han tenido que restablecer un orden en las estrofas del poema, quizá repartidas en varias cuartillas no numeradas. Todos los testimonios, salvo Índice, recogen sin apenas cambios dos estrofas -la que comienza con "Caballeros, salud y buena suerte" y la siguiente, "Le dejo al tabernero"-, pero estas secciones aparecen bien al principio, como en $P A(G S, G G S)$, o bien al final del poema $(M, C)$. La estructura cambiante de "Testamento" en su tradición impresa y en su versión extensa podría derivar de la transposición o cambio del orden de las estrofas, si el editor utilizó una cuartilla de un borrador del dosier como inicial o se decidió dejarla para la conclusión del poema. Este tipo de alteración podría considerarse una variante de transmisión o de copia, y no una variante de autor, ya que constituiría un cambio ajeno, como lo son probablemente también las diferencias en los signos de puntuación.

Con independencia de todo ello, la documentación indirecta y los testimonios analizados revelan al menos dos estados genéticos del poema, probablemente consecutivos, con variantes de lectura: uno más breve, con un texto de tres estrofas centrado en la crítica del reportero mezquino -testimonio Índice, si es que éste se presenta completo-, y otro más extenso, de 5 o 6 estrofas, dirigido a un destinatario más amplio, en el que se detallan las mandas del testamento con su reparto de bienes -todos los demás testimonios. La primera fase redaccional pudo tener su origen en un incidente de Valle-Inclán con un periodista concreto a finales de 1932, y la segunda, derivada de un cambio en las circunstancias personales, pudo estar relacionada con su polémica elección como director de la Academia de Roma en 1933. Con ello se cumpliría la situación más habitual en la práctica literaria: la versión más breve de un texto suele ser cronológicamente anterior a la versión más extensa. En todo caso, la única fecha segura de redacción en este dosier de génesis es la de la misiva dirigida a Ramón Pérez de Ayala: 4 de febrero de 1933. Todos los testimonios impresos son póstumos y, por lo tanto, no han sido controlados por el autor. El prime- 
ro de ellos se difundió en 1937 en la revista catalana Mirador y allí ha permanecido olvidado hasta la fecha.

El único testimonio sin correcciones ${ }^{35}$, copiado en limpio por el propio escritor, sin sospecha, por tanto, de imposición de alteraciones a causa de manos ajenas, y que consta de 5 estrofas totalmente regulares en su rima, es el que se presenta en la carta $(P A)$, aunque Valle-Inclán considere en ese momento el poema fragmentario y se proponga continuarlo en el futuro. Tal testimonio determina el estado genético del texto, en ese momento concreto, de una forma sólida dentro de este corpus híbrido tan inestable. Por semejantes razones, y a la inversa, se estima que el testimonio más deturpado sería el proporcionado por Ramón Gómez de la Serna en su justiciera biografía.

\section{REFERENCIAS}

Relación de testimonios de "Testamento"

\section{Manuscritos}

Índice = Índice de Artes y Letras, Madrid, 9, 74/75, mayo-junio 1954, p. 24. [Biblioteca Xeral de la Universidad de Santiago de Compostela].

$P A=$ Carta de Ramón del Valle-Inclán a Ramón Pérez de Ayala, Madrid, 4 de febrero de 1933; colección Rodríguez Porrero. [Biblioteca de Bartolomé March, Madrid; ilocalizable en la actualidad].

\section{Impresos}

$M=$ "Testamento improvisado en una tarde angustiosa por don Ramón del Valle-Inclán”, en "Un poema inèdit de Valle-Inclán”, Mirador. Setmanari de literatura, art i política, Barcelona, 9, 416, 15 de abril de 1937, p. 6.

GS = Ramón Gómez de la Serna 1944. Don Ramón María del Valle-Inclán, Espasa-Calpe, Austral, Buenos Aires, p. 200.

$C=$ Camilo José Cela 1950. "La peonza del 98. Las memorias de Baroja y la última cuartilla de Valle-Inclán”, Clavileño, Madrid, 2, marzo-abril, pp. 40-41.

GGS = Gaspar Gómez de la Serna 1958. "Valle-Inclán, más acá del medio siglo", en Ramón del Valle-Inclán, Obras escogidas, Aguilar, Biblioteca de Autores Modernos, Madrid, p. 11.

35 Recordemos que el de Índice presenta reescrituras y que puede estar incompleto. 


\section{Fuentes secundarias}

Alberca, Manuel y Cristóbal González 2002. Valle-Inclán. La fiebre del estilo, Espasa-Calpe, Madrid.

Ambía, IsABel de 1946. "Magia en la vida y en la obra de don Ramón María del Valle-Inclán”, Cuadernos de Literatura Contemporánea, 46, pp. 479-484.

Carabias, Josefina 1933. "Hablando con Valle-Inclán, nuevo director de la Academia Española de Bellas Artes de Roma”, La Voz, Madrid, 9 de marzo, p. 3.

Carabias, Josefina 1936. "La intimidad del gran don Ramón, «Reportero, te dejo mi cadáver»”, Crónica, Madrid, 8, 322, 12 de enero, pp. [10]-[11].

Carabias, Josefina 1981. Los que le llamábamos Don Manuel, Plaza y Janés, Barcelona.

"Ejemplo para los Ayuntamientos gallegos. El de Madrid organizará un homenaje en memoria de Valle-Inclán”, El Pueblo Gallego, Vigo, 9 de enero de 1936 , p. 1.

Fuente BAllesteros, Ricardo de la 2001. "Algunos autógrafos valleinclanianos y la Academia Española de Bellas Artes de Roma”, Hecho Teatral. Revista de Teoría y Práctica del Teatro Hispánico, 1, pp. 159-181.

Garlitz, Virginia M. 1995. "Cartas de Valle-Inclán a Pérez de Ayala con un comentario”, en A Ricardo Gullón: sus discípulos. Ed. Adelaida López de Martínez, Pub. de la Asociación de Licenciados y Doctores Españoles en Estados Unidos, Erie, PA, pp. 103-114.

Gómez de la Serna, Gaspar 1969. "I. Don Ramón del Valle-Inclán. 1. Perspectiva de centenario. 1. La máscara, el rostro, la obra”, en Entrerramones y otros ensayos, Editora Nacional, Madrid, pp. 9-10.

González Alonso, Pablo 1981. Cartas a los Machado, Diputación Provincial de Sevilla, Sevilla.

Hormigón, Juan Antonio 1987. Valle-Inclán. Cronología. Escritos dispersos. Epistolario, Fundación Banco Exterior, Madrid.

Hormigón, JuAn ANTONio 2006. Valle-Inclán. Biografía cronológica y epistolario. T. 3: Epistolario, Publicaciones de la Asociación de Directores de Escena de España, Madrid. (Teoría y práctica del Teatro, 26).

Juan Bolufer, Amparo de 2015. "Génesis e historia textual de El ruedo ibérico de Ramón del Valle-Inclán”, Boletín de la Biblioteca Menéndez y Pelayo, 91, pp. 15-59.

JuAn Bolufer, Amparo de 2018. “"Para ti mi cadáver, reportero». Las necrológicas de Ramón del Valle-Inclán”, en El retrato literario en el mundo hispánico. Coords. Jesús Rubio Jiménez y José Enrique Serrano Asenjo, Prensas Universitarias de Zaragoza, Zaragoza, pp. 165-198.

"La primera y última cuartilla de su obra póstuma”, El Sol, Madrid, 7 de enero de 1936 , p. 6.

“Las últimas cuartillas de Valle-Inclán”, La Voz, Madrid, 10 de enero de 1936, p. 2.

Molina Cantero, Camila 1988. "Índice de Artes y Letras: historia, estructura, contenido e ideología de una revista”, Boletín de la $A N A B A D, 38,4$, pp. $421-438$.

Rubia BARCiA, José 1960. A bibliography and iconography of Valle-Inclán (18661936), University of California Press, Berkeley-Los Angeles. [Ampliado 
y corregido en José Rubia Barcia, "A synoptic view of his life and works”, en Ramón del Valle-Inclán. An appraisal of his life and works. Ed. Anthony Zahareas, Las Américas, New York, 1968, pp. 3-34].

Rubio Jiménez, Jesús 2015. "Ramón Gómez de la Serna biógrafo de Ramón María del Valle-Inclán. Una aproximación”, Creneida, 3, pp. 150-182.

Rubio Jiménez, Jesús y Antonio Deaño Gamallo 2011. Ramón del ValleInclán y Josefina Blanco. El pedestal de los sueños, Prensas Universitarias de Zaragoza, Zaragoza.

Ruiz Contreras, Luis 1937. "El banc del «si no fos»", Mirador, 417, 22 de abril, p. 5.

Sagarra, Josep Maria de 1936. "L'aperitiu. Valle-Inclán”, Mirador, 8, 361, 16 de enero, p. 2. [Se recoge en Josep Maria Sagarra, El perfum dels dies. Articles a "Mirador" (1929-1936). Ed. Narcís Garolera, Quaderns Crema, Barcelona, 2004, pp. 442-445].

Santos Zas, Margarita 2012. "Los manuscritos de Valle-Inclán. El taller del escritor", en Crítica genética y edición de manuscritos hispánicos contemporáneos: aportaciones a una poética de transición entre estados. Coords. Bénédicte Vauthier y Jimena Gamba Corradine, Ediciones Universidad, Salamanca, pp. 159-174.

SERrA, NARciso 1888 [1861]. El loco de la guardilla: paso que pasó en el siglo XVII. Escrito en un acto y en verso por don Narciso Serra; música del maestro don Manuel Caballero, Establecimiento Tipográfico de M. Minuesa, Madrid.

Serrano Asenjo, Enrique 2002. Vidas oblicuas. Aspectos teóricos de la nueva biografía en España (1928-1936), Prensas Universitarias, Zaragoza.

Serrano Asenjo, Enrique 2005. "Las biografías de escritores de Ramón Gómez de la Serna y su poética encubierta: Los contemporáneos", Revista Canadiense de Estudios Hispánicos, 30, pp. 171-187.

Singla Casellas, Carles 2006. Mirador (1929-1937): un model de periodic al servei d'una idea de país, Institut d'Estudis Catalans, Barcelona.

Sotelo VÁzQuez, Adolfo 2008. "Valle-Inclán y las letras barcelonesas. Josep Maria de Sagarra y Alexandre Plana”, en Valle-Inclán: ensayos críticos sobre su obra y su trascendencia literaria. Ed. F. López Criado, Hércules, A Coruña, pp. 311-328.

"Valle-Inclán", Mirador, Barcelona, 8, 360, 9 de enero de 1936, p. 6.

Valle-Inclán, Ramón del 1932. "Réquiem", Blanco y Negro, Madrid, 424, 2159, 30 de octubre.

VAlle-InClán, RAMón Del 1987. Artículos completos y otras páginas olvidadas. Ed. Javier Serrano Alonso, Istmo, Madrid.

VAlle-Inclán, Ramón del 2002. Obra completa, Espasa-Calpe, Madrid.

VAlle-Inclán Alsina, Javier del 2016. "Os últimos meses de Valle-Inclán”, en Carlos G. Reigosa, Javier del Valle-Inclán y José Monleón, A morte de Valle-Inclán. O último esperpento, Xerais, Vigo, pp. 33-95.

"Vecinos sin concejales... El homenaje a la memoria de D. Ramón está en marcha”, La Voz, Madrid, 10 de enero de 1936, p. 3. 